\title{
The use of neodymium magnets in healthcare and their effects on health
}

\author{
Cengiz Yuksel, ${ }^{1}$ Seyit Ankarali, ${ }^{2}$ Nehir Aslan Yuksel ${ }^{1}$ \\ 1Department of Physiology, Institute of Health Sciences, Duzce University, Duzce, Turkey \\ ${ }^{2}$ Department of Physiology, Istanbul Medeniyet University Faculty of Medicine, Istanbul, Turkey
}

\begin{abstract}
The strong magnetic field properties of magnets have led to their use in many modern technologies, as well as in the fields of medicine and dentistry. Neodymium magnets are a powerful type of magnet that has been the subject of recent research. This review provides a brief explanation of the definition, history, and characteristics of rare earth magnets. In addition, a broad overview of results obtained in studies performed to date on the effects of magnets, and neodymium magnets in particular, on body systems, tissues, organs, diseases, and treatment is provided. Though they are used in the health sector in various diagnostic devices and as therapeutic tools, there is some potential for harmful effects, as well as the risk of accident. The research is still insufficient; however, neodymium magnets appear to hold great promise for both diagnostic and therapeutic purposes.
\end{abstract}

Keywords: Health; magnet; neodymium.

Cite this article as: Yuksel C, Ankarali S, Aslan Yuksel $N$. The use of neodymium magnets in healthcare and their effects on health. North Clin Istanb 2018;5(3):268-273.

$\mathrm{N}_{\mathrm{cos}}^{\mathrm{cot}}$ eodymium is a chemical element that was discovered in 1885. This element (atomic number 60) has a silvery-white metallic color and belongs to the group of lanthanides, which is a subgroup of rare earth elements (atomic numbers 57-71) in the periodic table and rapidly oxidizes in air. Lanthanides play important roles in new technological developments, such as wind turbines, electronic hybrid vehicles, and in the defense industry.

In nature, neodymium does not exist in metallic or in mixed forms with other lanthanides but is refined for general use and has been mined in the USA, Brazil, India, Australia, Sri Lanka, and predominantly in China.

Neodymium-iron-boron magnets were developed by General Motors and Hitachi in the 1980s. Because it provides high magnetic force even in lesser amounts, it has been increasingly given a more prominent role in the manufacture of strong permanent magnets made up of rare earth elements. In the field of information technol- ogy, neodymium magnets are particularly used in hard disc drives, mobile phones, video and audio systems of television [1].

Neodymium magnets are also commonly used in magnetic separators, filters, ionizers, in production of on-off buttons, safety sector and security systems. Grease filter producers use neodymium magnets in metal separators to more effectively filter out iron powder in oil. Additionally, they are beneficial in covering machines, cars with awning and in the production of magnetic tool belts. They are also used in jewelry clips, identification badges and in the production of baby strollers that are attached to carriers via magnets.

The health sector is another field where neodymium magnets are incorporated in medical devices for example in magnetic resonance imaging devices to diagnose and treat chronic pain syndrome, arthritis, wound healing, insomnia, headache, and several other diseases due to their

Received: June 01, 2017 Accepted: August 05, 2017 Online: April 12, 2018

Correspondence: Dr. Seyit ANKARALI. Istanbul Medeniyet Universitesi Tip Fakültesi, Fizyoloji Anabilim Dali, Istanbul,Turkey.

Phone: +902162804019 e-mail: seyitankarali@hotmail.com

(c) Copyright 2018 by Istanbul Provincial Directorate of Health - Available online at www.northclinist.com 
ability to generate a static magnetic field. An increase in their usage has been observed over the last decade [2]. These magnets are thought to have a curing effect and are therefore sometimes called "magic magnets".

NASA uses neodymium magnets to maintain the muscular tonus of astronauts during space flights [2].

Neodymium magnets have push-pull forces and have been used as a motion-generating device in orthodontic treatments; molar distillation, and palatal expansion [3, 4].

Static magnetic field has been reported to stimulate bone formation via osteoblastic differentiation or activation $[5,6]$.

The amount of neodymium magnets used in all these areas has risen from 1 ton to 60.000 tons between 1983 and 2007. Since 1990, China has been predominant in the mining of rare earth elements. The mining of rare elements has various environmental impacts because of the low concentration of these substances; therefore, many countries have stopped the mining of rare elements and almost all countries depend on imports from China [1].

\section{Effects of neodymium magnets on health and medical usage \\ Cardiovascular system}

In a study conducted in 2004, laser doppler was reported to significantly reduce blood flow and skin blood perfusion (SBF) in the $2^{\text {nd }}$ and $4^{\text {th }}$ fingers of the non-dominant hands of both poles of the neodymium magnet [7].

Another study indicated that neodymium magnetic fields increases the nail bed microcirculation although this study conflicted with other studies [8].

The flow of red blood cells in the skeletal muscle capillaries exposed to strong static magnetic fields has been reported to be reduced [9], Intra tumoral microcirculation is characterized by tortuous micro vessels with chaotic structures and unstable irregular blood flow. A study has reported a decrease in the blood stream and blood vessel density in tumors that were treated using static magnetic fields. In the same study, it was shown that in non-tumoral skeletal muscles exposed to static magnetic fields, platelet activation and adhesion increased [9]. The magnetic field generated by neodymium magnets is thought to increase microcirculation but the effects on this are not clearly known.

In a study, a special device was surgically placed on the backs of laboratory mice. Neodymium magnets were attached to the device in one group, and non-magnetic, equal-sized, and same-weight platters were attached in the other group. The arteriole and venule diameters of the mice exposed to static magnetic field generated by neodymium magnets were demonstrated to be considerably reduced [10].

Another study, conducted in 2015, where the portal veins of dogs were cut and reconstructed, the anastomosis in one group was performed using traditional manual sutures and that in the other group was by covering it with rings comprising of neodymium magnets. In the latter, the recovery lasted for a considerably short time and the intima was smoother and regularly formed than in the former [11].

Bipolar ablation catheters, unipolar ablation catheters and bipolar catheters with magnets attached to them have been tried in thick and tight tissues where it is hard to create a full-thickness lesion like in the left ventricular wall. Both the transmural passage and the thickness of the lesion formed by the magnetized bipolar catheter were found to be higher than others [12].

\section{Neural system}

Magnets can be used to generate magnetic fields in neural electrical activity research. The effect of magnetic fields created using neodymium magnets on neural damage was examined in a study where they were applied on 17 healthy volunteers for 2 hours. Neuron specific enolase which is the determinant of neuronal damage and S100 blood levels were studied, the test conducted to measure mental ability revealed that the parameters tested on the 17 volunteers were not affected by the magnetic fields and to generate a magnetic field with neodymium magnets seemed to be safe on these parameters [13].

Recurrent transcranial magnetic stimulation (rTMS) is an approved and effective treatment method for major depression. Synchronized TMS (sTMS), which is the modified form of rTMS, has also been tried for the treatment of the same. A study conducted in 2014 revealed that while the occurrence rate of patients who suffered from major depression and treated with sTMS declined by $48 \%$, it declined by $19 \%$ in the control group, and this difference was statistically significant. Neodymium magnets are used in TMS to generate magnetic fields and In contrast to electroconvulsive treatment for major depression, TMS does not require anesthesia [14]. Further, another study conducted in 2015 revealed the use of sTMS to be effective in the treatment of major depression [15]. Placing of magnets on upper and lower eyelids in the 
treatment of lagophthalmos has obtained successful results [16].

Alternative treatment methods including magnetic therapy have been researched on menopause vasomotor symptoms and it has been found that they are not effective in the treatment of these symptoms [17].

In another study, to ensure glottis aperture in bilateral vocal cord paralysis, magnets were placed ex vivo in sheep larynx had the gap widened. The device provide a suitable glottis aperture that benefit from magnets and this may be used in the future [18].

Skeleton, muscle, and joints system

The effect of neodymium magnet implants placed in rabbit tibia and that of non-magnetic implants on bone tissue have been compared. Magnetic implants reinforced both medulla and cortex around the bone tissue and the increase in the medulla was statistically significant [19].

In another study conducted using a trabecular damaged rabbit model, a magnetic scaffold was placed in the damaged area of the distal femoral epiphysis and cylindrical neodymium magnets $(\mathrm{NdFeB})$ were placed in a nearby area, the interaction observed. At the end of the experiment, it was found that $\mathrm{NdFeB}$ protects against micro movements by keeping the magnetic scaffold constant and it is important in maintaining regular tissue regeneration [20].

In a randomized double blind placebo controlled research, the curing effect of neodymium magnets on osteoarthritis symptoms was investigated; participants were made to try on four types of wrist straps. During the comparison, magnetic neodymium wrist straps were used as an experimental device, and low magnified, demagnetized, and coppery wrist straps were used as control devices. The WOMAC Osteoarthritis Index, McGill Pain Questionnaire-Pain Rating Index (PRI), visual analog scale, and medicine intake were evaluated. Among these scales, only PRI subscales revealed statistically significant difference. Therapeutic benefits of wrist straps have attributable placebo effect. These devices have no major adverse effects therefore can be used for placebo effect [21].

In another study, the difficulty of forming a control group where magnetic bracelets tested, addressed that giving a weakly effective wristband to the control group might not be effective in relieving pain in arthritis as the participant could test the strength of the wrist [22].
In a research in which the role of static magnetic field in carpal tunnel treatment was researched on, the effects of two different magnetic field levels on the median nerve were evaluated. In a randomized double blind placebo controlled research, 12-week long observation was performed after a 6-week long interference. Participants who were diagnosed with carpal tunnel syndrome using electrophysiological tests wore neodymium magnets and non-magnetic disks all night long. Boston Carpal Tunnel Questionnaire, symptom severity score (SSS), function severity score (FSS), and four parameters measuring the median neural activity were used. These parameters included sensory distal latency, sensory nerve action potential amplitude, motor distal latency, and compound motor action potential amplitude. Among the groups, no significant difference was found in SSS and FSS median nerve conduction. A recovery in symptoms was observed in a 6-week period for SSS and FSS in both groups. The change of symptoms in both magnetic and non-magnetic disc groups occurred in the same direction and size [23].

In two systematic reviews conduced in 2012 in which magnetic wristbands and several other alternative treatments were examined for arthritis, by citing the lack of enough research on the subject, it was concluded that there was no consistent evidence that it was effective for rheumatoid arthritis and osteoarthritis treatment $[24,25]$.

In a study, the effect of static magnetic field on the treatment of delayed onset muscle soreness revealed no difference with that of a placebo [26].

\section{Gastrointestinal system}

In a study conducted in 2012, neodymium magnets were used to fix endoscopically determined colon tumors. During the laparoscopic surgery performed without tools such as fluoroscopy or ultrasonography, the magnets were used for an easy access to the tumor. The intraoperative localization of marked lesions was successful in $27(96 \%)$ of 28 patients [27].

In an animal study, ring-shaped magnets were endoscopically used for magnetic compression anastomosis (magnamosis), being placed opposite to each other in the targeted areas [28, 29]. Magnets have also been surgically used in humans; unwanted tissues in the operative area were safely removed using magnetic forceps in 44 laparoscopic operations, including cholecystectomy, gastrojejunostomy, and splenectomy, performed on pediatric patients between 2009 and 2011 [30].

Previous studies on swallowed magnets have documented 
life-threatening injuries including, fistula and perforation, particularly in children. In two separate studies comparing the number and size of magnets swallowed by children in 2002-2009 and 2010-2012, there was an increase in the number of cases involving more than one magnet and a decrease in the size of the magnet swallowed, but all cases required surgical intervention. This result was attributed to an increase in the availability of magnets to children in everyday life [31]. These findings suggest that the use of magnets rather than safety pins can be particularly harmful for children. North Atlantic American Society for Pediatric Gastroenterology, Hepatology, and Nutrition advocated for the ban on the sale of strong magnets including neodymium, but they stated in 2014 that these efforts were not effective enough. [32].

\section{Magnet related injuries}

In a case report published in 2015 that led to the initiation of measures governing the use of magnets at the workplace, it was pointed out that a 52-year-old man was injured while trying to generate electricity for experimental purposes using a device containing neodymium magnets. The magnet crashed into pieces injuring his face. The report further discussed the difficulty of operating with strong magnets using traditional tools and the possible damages of uncontrolled movements caused by such tools. Accordingly, it was stated that there is also a need for medical equipment that are insensitive to magnetic effects [33].

Orientation of iron-containing nanoparticles

by magnets and their use in pharmacotherapy

Currently, magnetic iron oxide nanoparticles are used in several biomedical and neurobiological operations such as those performed for the monitoring and treatment of tumors.

A study reported that the attachment of oxide nanoparticles to the astrocytic membrane and their entrance into the cells becomes easier by virtue of the magnetic field generated by neodymium magnets laid under the astrocyte cells in the brain [34].

Human stem cells in serum-free medium, to which an amount of magnetic nanoparticles containing iron $(0.043 \mathrm{mg} / \mathrm{ml})$ was added in a nontoxic level, were used along with neodymium magnets and observed on a daily basis. No effect on stem cell prepotency and proliferation was recorded was reported in this study [35].

In a study conducted on pigs in 2014, vascular stents were rendered magnetic by means of neodymium magnets and, thus, ensured to hold to endothelium cells that were supported with iron particles. This may lead to an important development in stent-related procedures because the acceleration of endothelialization would reduce the risk of thrombosis [36].

An animal study published in 2012 had the orientation of stem cells containing iron particles to the targeted area in the retina again ensured with neodymium magnets. This appeared to be particularly important in the treatment of age-related macular degeneration and retinitis pigmentosa [37].

Nanoparticles loaded with cytotoxic chemotherapeutic agents can be oriented toward tumors. In tumor areas, capillary permeability increases and particles that cannot intercellularly travel elsewhere can pass into the tumor. This passage of nanoparticles can be reinforced through orientation by magnets [38].

In an experiment on aneurysm closure, magnets placed on the outer body of experimental rabbits were used to direct magnetic micro particles in the circulation toward the area for at least 30 minutes. Although aneurysmal recanalization was observed 12 weeks later during follow-up, this was an important study for possible new modalities in the treatment of aneurysms [39].

Another study conducted in 2014 showed that sperms exposed to magnetic field were more enduring [40].

\section{Use of magnets in dentistry}

Magnets have also been used in orthodontic operations. The outward movement of the buried tooth root in cases of dental fracture can be achieved using magnets in 9-12 weeks. The root reaching out can then be reformed by methods such as porcelain coating [41]. Neodymium magnets are used with coatings as they are not resistant to corrosion and gradual loss of strength [42].

\section{Conclusion}

Electronic devices are being increasingly used in our lives. Fossil fuels are being replaced by renewable energies, a field that increasingly uses rare earth elements. These elements are used in electric cars and wind turbines. Although procurement challenges and high prices lead producers to seek alternatives, rare earth elements are still being used in numerous technology and Because of their demand, the health effects of these powerful magnets must be addressed along with their environmental impacts. 
In this review, the history, definition, and properties of rare earth magnets were briefly explained. Additionally, basing on the results roughly examined from the studies carried out so far, we concluded that there are effects of magnets, especially neodymium magnets, on body systems, tissues, organs, diseases, and treatments. Although they have been used in various diagnostic devices in the health sector and as therapeutic tools, magnets are potentially harmful to the body and pose increased risk of accident. Despite insufficient studies conducted on the effects of neodymium magnets, they appear to have a great potential for both diagnostic and therapeutic procedures.

Conflict of Interest: No conflict of interest was declared by the authors.

Financial Disclosure: The authors declared that this study has received no financial support.

Authorship Contributions: Concept - S.A.; Design - S.A.; Supervision - S.A.; Materials - S.A., C.Y., N.A.Y.; Data collection \&/or processing - S.A., C.Y., N.A.Y.; Analysis and/or interpretation - S.A., C.Y., N.A.Y.; Writing - S.A., C.Y., N.A.Y.; Critical review - S.A.

\section{REFERENCES}

1. Du X, Graedel TE. Global rare earth in-use stocks in NdFeB permanent magnets. J Ind Ecol 2011;15:836-43. [CrossRef]

2. Colbert AP, Wahbeh H, Harling N, Connelly E, Schiffke HC, Forsten $\mathrm{C}$, et al. Static magnetic field therapy: a critical review of treatment parameters. Evid Based Complement Alternat Med 2009;6:133-9.

3. Noar JH, Evans RD. Rare earth magnets in orthodontics: an overview. Br J Orthod 1999;26:29-37. [CrossRef]

4. Tuncer C. Magnets and Applications in Orthodontics. GÜ Diş Hek Fak Derg 2006;23:131-5.

5. Ba X, Hadjiargyrou M, DiMasi E, Meng Y, Simon M, Tan Z, et al. The role of moderate static magnetic fields on biomineralization of osteoblasts on sulfonated polystyrene films. Biomaterials 2011;32:78318. [CrossRef]

6. Cunha C, Panseri S, Marcacci M, Tampieri A. Evaluation of the effects of a moderate intensity static magnetic field application on human osteoblast-like cells. Am J Biomed Eng 2012;2:263-8. [CrossRef]

7. Mayrovitz HN, Groseclose EE. Effects of a static magnetic field of either polarity on skin microcirculation. Microvasc Res 2005;69:24-7.

8. Yan Y, Shen G, Xie K, Tang C, Wu X, Xu Q, et al. Wavelet analysis of acute effects of static magnetic field on resting skin blood flow at the nail wall in young men. Microvasc Res 2011;82:277-83. [CrossRef]

9. Strieth S, Strelczyk D, Eichhorn ME, Dellian M, Luedemann S, Griebel $\mathrm{J}$, et al. Static magnetic fields induce blood flow decrease and platelet adherence in tumor microvessels. Cancer Biol Ther 2008;7:814-9.

10. Morris CE, Skalak TC. Chronic static magnetic field exposure alters microvessel enlargement resulting from surgical intervention. J Appl Physiol (1985) 2007;103:629-36. [CrossRef]

11. Wang SP, Yan XP, Xue F, Dong DH, Zhang XF, Ma F, et al. Fast magnetic reconstruction of the portal vein with allogeneic blood vessels in canines. Hepatobiliary Pancreat Dis Int 2015;14:293-9. [CrossRef]

12. Lee C, Choi EK, Kong HJ, Choy YB, Kim HC, Oh S. Generating radiofrequency ablation lesions using magnetically coupled bipolar catheters. Pacing Clin Electrophysiol 2011;34:934-8. [CrossRef]

13. Oliviero A, Carrasco-López MC, Campolo M, Perez-Borrego YA, Soto-León V, Gonzalez-Rosa JJ, et al. Safety Study of Transcranial Static Magnetic Field Stimulation (tSMS) of the Human Cortex. Brain Stimul 2015;8:481-5. [CrossRef]

14. Jin Y, Phillips B. A pilot study of the use of EEG-based synchronized Transcranial Magnetic Stimulation (sTMS) for treatment of Major Depression. BMC Psychiatry 2014;14:13. [CrossRef]

15. Leuchter AF, Cook IA, Feifel D, Goethe JW, Husain M, Carpenter LL, et al. Efficacy and Safety of Low-field Synchronized Transcranial Magnetic Stimulation (sTMS) for Treatment of Major Depression. Brain Stimul 2015;8:787-94. [CrossRef]

16. Barmettler A, Nissanka N, Rosenblatt MI, Rao R, Lipson D, Lelli GJ Jr. Magnetic systems for tarsorrhaphy. Ophthal Plast Reconstr Surg 2014;30:305-8. [CrossRef]

17. Pinkerton JV, Stovall DW, Kightlinger RS. Advances in the treatment of menopausal symptoms. Womens Health (Lond) 2009;5:361-84.

18. Ciftci Z, Deniz M, Ciftci HG, Ozdemir DN, Isik A, Gultekin E. Magnetic Control of the Glottic Opening in an Ex Vivo Sheep Larynx Model: A Preliminary Study. J Voice 2016;30:621-5. [CrossRef]

19. Leesungbok R, Ahn SJ, Lee SW, Park GH, Kang JS, Choi JJ. The Effects of a Static Magnetic Field on Bone Formation Around a Sandblasted, Large-Grit, Acid-Etched-Treated Titanium Implant. J Oral Implantol 2013;39:248-55. [CrossRef]

20. Panseri S, Russo A, Sartori M, Giavaresi G, Sandri M, Fini M, et al. Modifying bone scaffold architecture in vivo with permanent magnets to facilitate fixation of magnetic scaffolds. Bone 2013;56:432-9.

21. Richmond SJ, Brown SR, Campion PD, Porter AJ, Moffett JA, Jackson DA, et al. Therapeutic effects of magnetic and copper bracelets in osteoarthritis: a randomised placebo-controlled crossover trial. Complement Ther Med 2009;17:249-56. [CrossRef]

22. Greaves CJ, Harlow TN. Exploration of the validity of weak magnets as a suitable placebo in trials of magnetic therapy. Complement Ther Med 2008;16:177-80. [CrossRef]

23. Colbert AP, Markov MS, Carlson N, Gregory WL, Carlson H, Elmer PJ. Static magnetic field therapy for carpal tunnel syndrome: a feasibility study. Arch Phys Med Rehabil 2010;91:1098-104. [CrossRef]

24. Macfarlane GJ, Paudyal P, Doherty M, Ernst E, Lewith G, MacPherson $\mathrm{H}$, et al; Arthritis Research UK Working Group on Complementary and Alternative Therapies for the Management of the Rheumatic Diseases. A systematic review of evidence for the effectiveness of practitioner-based complementary and alternative therapies in the management of rheumatic diseases: rheumatoid arthritis. Rheumatology $(\mathrm{Ox}-$ ford) 2012;51:1707-13. [CrossRef]

25. Macfarlane GJ, Paudyal P, Doherty M, Ernst E, Lewith G, MacPherson $\mathrm{H}$, et al; Arthritis Research UK working group on Complementary and Alternative Therapies for Management of Rheumatic Diseases. A systematic review of evidence for the effectiveness of practitioner-based complementary and alternative therapies in the management of rheumatic diseases: osteoarthritis. Rheumatology (Oxford) 2012;51:2224-33. [CrossRef]

26. Mikesky AE, Hayden MW. Effect of static magnetic therapy on recovery from delayed onset muscle soreness. Phys Ther Sport 2005;6:188-94.

27. Warnick P, Chopra SS, Raubach M, Kneif S, Hünerbein M. Intraoperative localization of occult colorectal tumors during laparoscopic surgery by magnetic ring markers-a pilot study. Int J Colorectal Dis 
2013;28:795-800. [CrossRef]

28. Jamshidi R, Stephenson JT, Clay JG, Pichakron KO, Harrison MR. Magnamosis: magnetic compression anastomosis with comparison to suture and staple techniques. J Pediatr Surg 2009;44:222-8. [CrossRef]

29. Pichakron KO, Jelin EB, Hirose S, Curran PF, Jamshidi R, Stephenson JT, et al. Magnamosis II: Magnetic compression anastomosis for minimally invasive gastrojejunostomy and jejunojejunostomy. J Am Coll Surg 2011;212:42-9. [CrossRef]

30. Padilla BE, Dominguez G, Millan C, Martinez-Ferro M. The use of magnets with single-site umbilical laparoscopic surgery. Semin Pediatr Surg 2011;20:224-31. [CrossRef]

31. Strickland M, Rosenfield D, Fecteau A. Magnetic foreign body injuries: a large pediatric hospital experience. J Pediatr 2014;165:332-5.

32. Bousvaros A, Bonta C, Gilger M, Noel RA. Advocating for child health: how the North American Society for Pediatric Gastroenterology, Hepatology, and Nutrition took action against high-powered magnets. J Pediatr 2014;164:4-5.e1. [CrossRef]

33. Aykan A, Güzey S, Avşar S, Öztürk S. Neodymium magnet injury causing nasal fracture: a case report. Ulus Travma Acil Cerrahi Derg $2015 ; 21: 231-4$.

34. Lamkowsky MC, Geppert M, Schmidt MM, Dringen R. Magnetic field-induced acceleration of the accumulation of magnetic iron oxide nanoparticles by cultured brain astrocytes. J Biomed Mater Res A 2012;100:323-34. [CrossRef]
35. Freitas ER, Santos RL, Lima EC, Guillo LA. Feeder-free culture of human embryonic stem cell line BG01V/hOG using magnetic fieldmagnetic nanoparticles system. Biomed Pharmacother 2013;67:17-21.

36. Uthamaraj S, Tefft BJ, Klabusay M, Hlinomaz O, Sandhu GS, Dragomir-Daescu D. Design and validation of a novel ferromagnetic bare metal stent capable of capturing and retaining endothelial cells. Ann Biomed Eng 2014;42:2416-24. [CrossRef]

37. Yanai A, Häfeli UO, Metcalfe AL, Soema P, Addo L, Gregory-Evans $\mathrm{CY}$, et al. Focused magnetic stem cell targeting to the retina using superparamagnetic iron oxide nanoparticles. Cell Transplant 2012;21:113748. [CrossRef]

38. Klostergaard J, Seeney CE. Magnetic nanovectors for drug delivery. Nanomedicine 2012;8 Suppl 1:S37-50. [CrossRef]

39. Oechtering J, Kirkpatrick PJ, Ludolph AG, Hans FJ, Sellhaus B, Spiegelberg A, et al. Magnetic microparticles for endovascular aneurysm treatment: in vitro and in vivo experimental results. Neurosurgery 2011;68:1388-97. [CrossRef]

40. Lee SH, Park CK. Effect of magnetized extender on sperm membrane integrity and development of oocytes in vitro fertilized with liquid storage boar semen. Anim Reprod Sci 2015;154:86-94. [CrossRef]

41. Bondemark L, Kurol J, Hallonsten AL, Andreasen JO. Attractive magnets for orthodontic extrusion of crown-root fractured teeth. Am J Orthod Dentofacial Orthop 1997;112:187-93. [CrossRef]

42. Yiu EY, Fang DT, Chu FC, Chow TW. Corrosion resistance of ironplatinum magnets. J Dent 2004;32:423-9. [CrossRef] 